\title{
Effect of a Video-Based Laboratory on the High School Pupils' Understanding of Constant Speed Motion
}

\author{
Louis Trudel \\ Faculté d'éducation \\ Université d'Ottawa \\ Ottawa, Canada
}

\author{
Abdeljalil Métioui \\ Département de didactique, Faculté des sciences de \\ l'éducation, Université du Québec à Montréal, \\ Montréal, Canada
}

\begin{abstract}
Among the physical phenomena studied in high school, the kinematical concepts are important because they constitute a precondition for the study of subsequent concepts of mechanics. Our research aims at studying the effect of a computer-assisted scientific investigation on high school pupils' understanding of the constant speed motion. Experimentation took place in a high school physics classroom. A repeated measures analysis of variance shows that, during the implementation of this strategy, the pupils' understanding of kinematical concepts increased in a significant way. In conclusion, we specify advantages and limits of the study and give future research directions concerning the design of a computer-assisted laboratory in high school physics.
\end{abstract}

Keywords-speed; computer-assisted laboratory; understanding; high school; Rasch measurement

\section{INTRODUCTION}

In reaction to what some people called traditional physics education, constituted by lectures followed by sessions of exercises and verification of theories in the laboratory, Anderson [1] recommends that the pupil plays a more active role by constructing his knowledge under the supervision of the teacher. In this approach, called guided discovery, learning results from activities of putting to the test by experiments the pupils' ideas about motion phenomena. However, experiments offered to the pupils in physics lessons do not usually take into account their alternative schemas in relation to the speed so that they can experience difficulties in identifying the appropriate factors and expressing them quantitatively in the form of equations. Therefore, our first research objective aims at conceiving and identifying the conditions of implementation of a strategy of scientific investigation which takes into account alternative schemas of the pupils and allow them to prove their hypotheses in the laboratory. Our second research objective consists in assessing the effect of such a strategy on the high school pupils' understanding of the constant speed concept. In the second section, we present a review of the literature concerning difficulties of the pupils in kinematics and the use of the computer-assisted laboratory to palliate these difficulties. In the third section, we describe a somewhat specialized version of the computer-assisted laboratory, which is called the video-based laboratory (VBL), and specify the conditions in which it was implemented in a high school. In the fourth and fifth sections, we present the methodology used and the results obtained with respect to the evaluation of the effect of the VBL on the high school pupils' understanding of motion at constant speed. A discussion will follow in the sixth section on the conditions of implementation of the VBL and its effects on the pupils' understanding of kinematics. In conclusion, we draw the limits of our study and suggest directions for future researches.

\section{REVIEW OF LITERATURE}

If there is a domain which causes a lot of difficulties to the pupils, it is kinematics, defined as the study of the motion of objects without being concerned about its causes [2]. There are two main reasons put forward by the researchers: alternative schemas which the pupils already have on the properties of motion and the emphasis put on the mathematization of its properties in the teaching of kinematics. Firstly, the pupils have, before arriving in the physics course, a broad experience about the properties of motion which they have acquired in their interactions with daily events. These experiences allowed them to construct schemas with which they can interpret the phenomena of motion [3]. Particularly, these schemas resemble those developed by historical figures such as Aristote [4]. These schemas are completely adapted to the common life tasks: drive a bike, catch an object, etc. However, these schemas may differ from scientific concepts. In certain cases, these schemas may even interfere with learning, especially if the teacher does not take them into account. In that case, there is great danger that the pupils differentiate school knowledge, which works in the school (for instance, in the laboratory), of daily knowledge, who allows them to react with effectiveness to events of the common life [2]. Secondly, during laboratory activities, kinematics is often approached with the aid of a mathematization to which the pupils are not accustomed [2]. For instance, a common pedagogic technique consists in bringing the pupils, at the beginning of the study of kinematics, to the laboratory where they measure different properties of motion which they then put in graphs. Back in class, they analyze their results and perform calculations with the aid of mathematical expressions to get the values of the speed and acceleration. And yet, it appears that the pupils perform these various operations without a real understanding of what they are doing [2,5]. In this respect, during the laboratory activities, it seems that the pupils do not have enough opportunity to propose their own hypotheses [2,6,7]. Indeed, a study of protocols offered by the science laboratory textbooks in 
Quebec shows that the pupils have seldom the opportunity to get involved in genuine research, since textbooks laboratory protocols put generally emphasis on the procedures of data collecting and analysis [8].

To overcome these difficulties and propose more genuine investigation of kinematical phenomena, the use of technology would make easier the data collecting and analysis while supporting the pupil in his investigation of scientific phenomena [9]. In this approach, called 'video-based laboratory' or VBL, the motion of objects are recorded as videos, treated by softwares allowing at the same time the measure of the positions of objects according to time and the organization of these data in tables and graphs. Such an approach has several advantages: 1) it allows the pupil to focus on the generation of hypotheses and the interpretation of results, two skills not much developed in traditional laboratories [10]; 2) it allows the pupil to generate and to prove several hypotheses much faster, by making easier strategies of variation of parameters necessary for the formulation of hypotheses regarding the properties of phenomena [11,12]; 3) in physical situations where it is necessary to come back on the results of an experience to check the accuracy of the results obtained or possibly to change the original hypothesis, VBL can allow the traditional laboratory to become iterative in spite of the school constraints with respect to time or equipment. In effect, it is often necessary for the pupil to come back on the results of an experience to study the reasons of the gap between his ideas and his experimental results, thus favoring conceptual change in sciences $[13,14]$.

\section{CONCEPTION, IMPLEMENTATION AND EVALUATION OF THE VIDEO-BASED LABORATORY}

As regards the activities of conceptual change of kinematics phenomena, we conceived them in order to study the characteristics of constant speed motion. In the first section, we describe how we conceive the video-based laboratory. In the second section, we describe how the planned activities went ahead in the classroom. In the third section, we present the comments of both the pupils and their teacher about how they evaluate the activities. Finally, in the last section, we draw limits and propose improvements to the VBL to envision its future scope.

\section{A. Conception of the video-based laboratory}

To allow the pupils to work in small groups of four or five persons, we conceived a guide of activities allowing supervising the steps of the pupils. The guide introduces two cases of constant speed motion to study different aspects of this type of motion. These two cases consist of activities (questions, graphics to draw, etc.) which guide the modelling process of the pupils. The process of conceptual change is structured as a POE task (Prediction> Observation> Explanation) [15]. Every POE task takes place in the following way. A physical situation represented under a concrete form by a physical set-up is explained to the pupils in the guide. Questions linked to this case ask the pupil to predict what is going to arrive if experience is to be performed and to write them in their notebook. Once written, they compare their predictions with their peers in small group discussions to reach a general agreement. Upon agreement, each group send their representative to present their predictions to the whole class. In this step, teacher acts as a facilitator, asking questions to get pupils clarify their ideas. Then, when all teams have presented their ideas, the teacher demonstrates the phenomenon in front of the pupils and records it under video form with the help of pupils' volunteers. These videos are then transferred to USB keys and distributed to every team. Having inserted these sequences of pictures in the REGAVI1 software, the pupils of every team can then, with the aid of a cursor, take measures of the successive positions of the ball according to time. These measures are automatically put in tables by REGAVI. Later, these tables can be transferred for analysis to the REGRESSI2 software [16]. This last software possesses functions allowing the pupil to produce different graphs of position and speed according to time. As such, REGRESSI makes easier the discovery of relations between variables by providing means to compare the adjustment of different curves (linear, quadratic, exponential, etc.) in gathered data. At last, the pupils try then to explain the gaps, if need be, between their predictions and their results.

The role of the teacher in the VBL is to introduce activities to the pupils, to allocate roles to the pupils during small group discussions, to perform the demonstration of every case of motion in front of the pupils, to record these movements under video form and to distribute them to the pupils and, finally, to make easier exchanges between the pupils during whole class discussion [7]. In order to do so, we planned a training period of two hours duration, conducted by the main researcher, where the teacher could master the elements of the VBL and practice the skills to conduct discussions efficiently [7]. As regards the adaptation of the approach to the schoolroom, both the main researcher and the teacher met, throughout research, to undertake adjustments requested according to the evolution of pupils' understanding. Besides, two supplementary meetings prior to the implementation allowed the teacher to gain knowledge of the approach and the main researcher to add modifications in order to adapt the activities to the context of the school and to the characteristics of the pupils.

Regarding uniform straight motion, the first case subjected to the pupils is represented in the guide in the following way: « A ball is thrown on a horizontal rail. The circle in grey points out its initial position at the time of launching. The circle with symbol 1 inside points out the position of the ball after 1 second (see fig. 1) ».

\footnotetext{
${ }^{1}$ The REGAVI software allows the collection of data from a video of an object in motion in form of AVI file. This software contains functions allowing the measure of the successive positions of this object which it organizes in form of tables. It is possible later to transfer these data in the file REGRESSI to aims of analysis (see the following site: www.micrelec.fr/equipelabo/pics_art/pdf/M0314G26.pdf · PDF file).

2 The REGRESSI software accomplishes Cartesian graphs of data transferred to a data collection software such as REGAVI. REGRESSI also contains functions allowing to calculate new variables (speed, acceleration) from the measurements of position and of time, to find the best curve of group of experimental points, etc.
} 


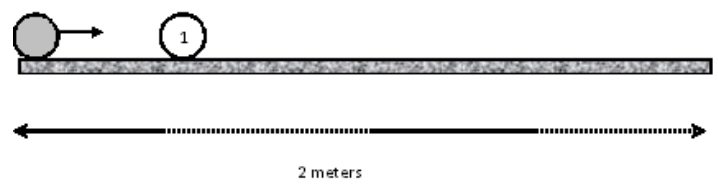

Figure 1. Motion of a ball traveling a horizontal rail.

The POE task consists then in predicting what will be the successive positions of the ball in the following seconds, knowing the distance gone through in the first second. From these predictions, the guide asks the pupils to draw a graph of what would be the curve of position according to time. Later, the pupils observe the motion of the ball when their teacher demontrates the phenomenon in front of them. After doing it several times, the teacher records the motion of the ball with the digital camera as a video. The video is then distributed to the different teams for data collection and analysis. These different steps allow the pupils to produce graphs of position and speed according to time in order to compare their predictions with their results and to change their hypotheses, if need be.

Regarding the second case of uniform straight motion, it is presented to the pupils in the guide in the following way: A light impulse is given to the ball (A) so as to make it move from an end of a horizontal rail of 2 metres to the other. The position of the ball (A) after 1 second is pointed out in figure 2 . Some seconds later, a second ball (B) is pushed with a bigger impulse than the ball A on a parallel rail to the first (fig. 2). With respect to the prediction, the guide asks the pupils to draw by hand on the figure 2, the positions he expected the balls (A) and (B) will be during the seconds following the impulsion. They also have to answer the following question: Do you think that the ball (B) will catch the ball (A)? If yes, they have to point out by one $\mathrm{X}$ the place where the two balls may go side by side and explain their answer. The steps of experience and explanation take place as in the first case described before.

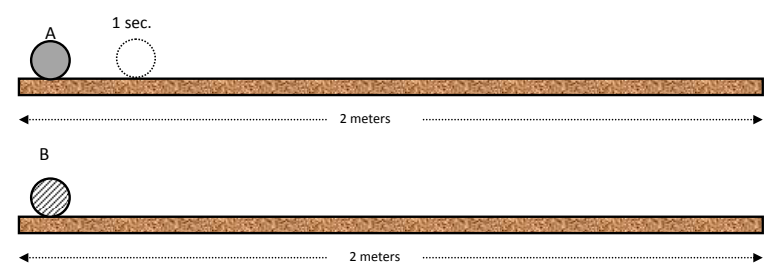

Figure 2. Motion of two balls moving at different speeds on two horizontal parallel rails

\section{B. Unfolding of activities}

Our pilot study consisted of a class of 32 French-speaking pupils attending a physics course in a high school of the province of Ontario in Canada. Research took place at the beginning of the second semester. It is to note that the school where took place the research had adopted a calendar where lessons, which normally stretch over all school year, were condensed in one semester. Consequently, the lessons of the first semester differed from the lessons of the second semester3. To study the implementation of the VBL, the main researcher held a research diary where he recorded his observations on the sequence of events, the critical details regarding the introduction of the VBL by the teacher, comments of the teacher in meetings with the main researcher, and links that the main researcher could establish between his observations and the theoretical framework of the present research [17]. During the experimentation, the main researcher or one of his research assistants were present at each of the periods to observe the upfolding of the events and take the measures of pupils' understanding. The main researcher or one of his assistants also played the role of monitor of laboratory, to solve the difficulties which may arise with the experimental set up or the use of data and analysis software by the pupils.

Activities took place in a physics laboratory distinct from the schoolroom. This place was suitable for our research, because it had several mobile tables that could be regrouped in small islets where the pupils could work in small teams. A unique set up allowing the demonstration of the cases of motion was located at the front of the class at short distance from the islets. The VBL described in the previous paragraph was implemented in the 11th grade physics course during five successive periods of one hour and quarter at the very beginning of the second semester. During the period immediately preceding the beginning of research, fifteen minutes had been dedicated at the end of the period to introduce the research to pupils.

As a matter of fact, during these last fifteen minutes, the teacher introduced the pupils to the research objectives, briefly described the activities and the time it would take and answered their questions. Furthermore, the teacher mentioned that these activities were part of the curriculum, that he was going to animate them with the materials provided by the main researcher and as a result all pupils had to participate in it. The teacher then divided the pupils in eight groups of three to four pupils of various skills. Moreover, the main researcher distributed to the pupils a letter of consent which their parents had to sign and returned to the main researcher at the end of the five periods dedicated to the research. At the end of the prior period, five minutes were dedicated to the completion of a quiz where the pupils had to answer a question testing their initial understanding of kinematics.

During the first period, the teacher present to the pupils the physical set up of the first case (see fig. 1), without performing the demonstration nevertheless. He asks them to write individually in their guide their predictions, i.e. to draw the successive positions of the ball on the horizontal rail as well as to draw what they expect would be the position-time and speed-time graphs. Then in small teams, the pupils discuss their answers to reach a general agreement which they write on large paper sheets. Once students have ended this last step, the teacher asks a representative of every team to present their predictions to the whole class. During their presentation, the teacher asks them questions to clarify their ideas. Because of time constraints, only the first six teams could make their

\footnotetext{
${ }^{3}$ In Canada, the school year is divided into two semesters each of a length of four months.
} 
presentations. During the last five minutes, the pupils answer a question of understanding.

During the second period, the teacher invites the last two teams to present their predictions to the class. After these presentations, the teacher then calls two pupils to volunteer for doing the demonstration of the phenomenon. All groups remain attentive except for a group located at the back of the class. The pupils point out very quickly that the rail is not perfectly horizontal and issue hypotheses on the reason for which it would not be so; in this respect, the pupils call into question the precision of measurements and the horizontality of the table. The ball is then lightly thrown by the volunteers so that the class can better notice the motion of the ball. The teacher mentions then to the pupils that it is necessary, besides observing the motion of the ball, to take measures of positions according to time if they want to prove their hypotheses and to compare them with their predictions. In order to do so, the teacher, helped by two volunteers, records a video of the motion, which is then copied on USB memories by one of the research assistants and later given to every team so that the pupils can download the video on their computer. The teacher announces to the pupils that they are now going to analyze data with the aid of the software REGAVI and REGRESSI to prove their ideas on the motion. In this respect, it was planned to broadcast with a projector the tutorials to the whole class. Because of technical problems, we asked the pupils to listen to the videos in group of two4. Our observations point out that the pupils are engaged in the listening of tutorials, that some of them take notes, that they explain software functions to each other and that they begin at the same time studying the motion recorded on video. Once the REGAVI software is understood, the pupils undertake the measurement of the positions of the ball according to time to constitute a table. They export this table towards the REGRESSI software where they produce both the graphs of position and speed according to time. In this respect, most of the teams could obtain their position-time and speed-time graphs which they record on their USB key and give it back to the research assistants. Upon reception of these, the assistants print for every member of the team both graphs which will be analyzed in the next period. Since this step is critically important for the activities of the third period, the research group and the teacher decides to report the measure of the understanding planned at the end of period to the beginning of the next period.

As a consequence, at the beginning of the third period, the pupils answer a question of the quiz. Then the teacher distributes the graphs of position-time and speed-time produced the period before to the pupils. He mentions them that they have to answer the questions of the explanation part of the first case. He passes from one team to the other to supervise their work. With the aid of a projector linked up with a computer, the teacher makes a review with the pupils of their answers by choosing the graphs produced by the pupils. The pupils answer the questions of the teacher with respect to these graphs. In the second half of this period, the teacher present the set-up of case 2 (see fig. 2) to the pupils. The sequence of the activities of the

\footnotetext{
${ }^{4}$ To increase participation of all pupils in the data collecting and analysis, two computers were allocated to each team of four pupils so that they could work by subteams of two.
}

second case is similar to the first case. The study of case 2 extended from the second half of the third period to the middle of the fifth period (that is during two periods as the first case). During the second half of the fifth period, the research assistant animates a discussion with the various teams, asking pupils prepared questions about benefits and difficulties they have experienced with the activities and gathers their comments with a recorder.

\section{Evaluation of the implementation of the VBL in the classroom}

The implementation of the VBL was assessed by the pupils and by the teacher with the aid of semi-directed discussions envisaged at the end of research. As regards the evaluation by the pupils, their comments and suggestions were gathered during discussion in small groups by one of the research assistants. As regards the evaluation of the activities by the teacher, his comments and suggestions were gathered during an interview conducted by the main researcher at the end of activities. We shall analyze the comments of the pupils in the first subsection and those of the teacher in the second.

1) Evaluation of the activities by the pupils: The pupils made comments about the following topics: the benefits of the activities, the difficulties they had to face, the easiness of use of technology (digital camera, soft wares of collection and analysis of information), the pertinence of activities in relation to the study of the concepts of motion, their suggestions or recommendations to improve the activities, their criticisms and the limits they saw with respect to the activities. As regards the benefits of activities, a pupil mentioned that it was good for visual persons and those who liked technology. Several pupils mentioned that they acquired new knowledge about motion, for example that the ball, contrary to their expectations, rolled at constant speed on the horizontal rail. Besides, some pupils could make links with what they had already known, notably with the notions of graph and slope which they had seen in the mathematics lessons. Another pupil mentioned the concrete character of activities which he preferred to written exercises because he could manipulate and touch. Another pupil found activities more interesting than to be in class. Regarding activities, a pupil mentioned that he had made physics without realizing it. Finally, a pupil mentioned that he had learnt to use computer programs and to insert them into physics. As regards the pertinence of activities, almost all pupils mentioned that activities were appropriate to learn motion, that they had learnt a lot and that this was going to be of use for them in their physics course.

2) As regards encountered difficulties, a pupil mentioned that he would have preferred making more experiments rather than to waste his time explaining hypotheses. In the same vein, another pupil lamented that he had not sufficient knowledge to compare with laboratory results. Several pupils mentioned difficulties in the collection of data: 1) the use of the paving rather than the mouse made the measurement of the various positions of the ball long and difficult; 2) balls being the same colour as the rail, it was sometimes difficult to differentiate between them, and that generated measurement errors. For the same reason, it was also difficult in the second case to differentiate between both balls when they were in the same 
position. In this respect, some pupils suggested to use balls of different colour to make measurement easier. The majority of the pupils mentioned problems associated with the tutorials to which they reproached their lacking suppleness. Hence, while using them, the pupils could not make a pause or come back to listen again to an explanation. According to pupils, these tutorials contained too many steps to follow, so they had to listen again to the whole band if they had not understood the first time. Moreover, some pupils experienced difficulties in producing graphs with the REGRESSI software.

\section{3) Evaluation of activities by the teacher:}

During the interview at the end of research, the main researcher and the teacher discussed about the same topics as during small group discussions with the pupils (see previous subsection). Above all, the teacher spotted indications that the pupils learned kinematics because, for example, they could express themselves in their own words and they were clear regarding what they meant about motion. From day to day, the teacher could see the progress of his pupils because their questions were more definite, their comments more appropriate. According to the teacher, the pupils were more advanced than ordinarily in the study of kinematics, a sign that they progressed tremendously. Certain pupils spoke about the force of gravity. A pupil even linked up the force of gravity with friction. According to the teacher, the pupils used force notions which were not necessarily what they needed for the study of motion, but that were linked up in fact, but they went farther than when we teach in a lecture. Therefore, according to him, the activities have the pupils question themselves, discuss so that they get a broader overview in fact than what they have habitually in kinematics. Consequently, during the second case, the teacher noticed that several teams had succeeded in predicting the outcome of the phenomenon (see previous subsect.).

As regards the experimental method, the teacher noticed that the pupils discussed even during pauses or before the lessons of their predictions and their hypotheses concerning motion. They exchanged on their predictions in form of hypotheses and on the manner of proving them. According to the teacher, it is not necessarily what the pupils do in the physics course, partly because of the lack of equipment, but also because of the emphasis put on problem solving. However, during the VBL activities, the pupils could apply the scientific method. Besides, the teacher is of the opinion that the pupils gained knowledge of the use of technology in the laboratory, taken into account the graphs which they produced and that were well made. As regards the curriculum, the teacher considers that the activities were in line with the objectives associated with uniform motion. In effect, according to him, the pupils did graphic analysis, approached the mathematical notions of slope and studied notions to understand uniform movement, as well as factors which influence it, and as a result they covered practically about half of the unit in motion. With respect to the follow up to be given to the VBL activities, the teacher plans now to make a quick flyover because he considers that the pupils had covered the majority of the notions of uniform straight motion.

According to the teacher, the difficulties met by the pupils consisted especially in gaining knowledge of the software of data collection and analysis. But once this objective was achieved, the teacher realized that, especially during the second case, the pupils could perform the same tasks (collection and analysis of data) as in the first case in only fifteen to twenty minutes. As regards the large number of pupils for a science class (32), the break up in small teams helped a lot as well as the arrangement of tables in the form of islets. This disposition allowed the pupils to work well all the more so as they were divided in team of different skills, some pupils having more skills in sciences, others in communication. This sharing out in different skill groups was preferable according to him to groups of pupils urged just to calculate. As regards technical difficulties, they were minimized by the focus placed upon the study of only two cases, which simplified the task of the teacher to help the pupils use the software.

\section{Future scope}

Since this part is concerned mostly with envisioning what would be the limits and possible range of the VBL, the comments gathered are mainly the teacher say. As such, the pupils mainly comments on the concrete aspects of the VBL, their difficulties encountered with the softwares, with the data collection and analysis, etc. Regarding improvements, the teacher suggests introducing the pupils to the data collecting and analysis softwares with the aid of already available experiments store into a data bank. The pupils could so gain knowledge of the softwares before the experimentation really begins. Thus, it could save time during the first activities and help the class keep a good rhythm with respect to content coverage. This training would not necessarily be long, at the very most thirty minutes. Moreover, he considers that tutorials representing and explaining the functioning of software helped a lot the pupils. With respect to the guide, he noticed that the pupils have the impression that the questions repeat themselves. However, the teacher is not sure that his pupils did not understand either the sense of the questions or the concepts itself. Taken into account this situation, the teacher explains that, for some of his pupils, French is not their mother tongue so that the shape of sentences could put them off. Besides, the cultural aspect could influence their understanding of questions because certain pupils do not understand certain terms which bear contextual, cultural or social references.

As regards the limits of activities, the teacher mentions that the time constitute the main limit. Indeed, he thinks that to dedicate five periods to this type of activities is really appropriate, but that if it had to persist, he fears losing the interest of the pupils, as besides for any other type of activities. He considers that after some time, it becomes repetitive, the set-up, the equipment. However, he noted that even so the pupils participated till the end. As regards the incorporation of activities in the curriculum, he considers that they are well integrated with the curriculum. However, the teacher pointed out a problem concerning the perception of the pupils who don't consider these activities being real learning. This is in line with some pupils comments about how they had learnt a lot and that it would be beneficial to them in their physics course. In this respect, the teacher wonders if to persuade them, they should be assessed midway so they could see their progress. According to the teacher, it is probable that the pupils are not accustomed to this method and it is only later they are 
going to realize that they understand all this. However, noticing the manner the pupils discussed with him, the way they answered questions in the guide, how they worked, he could point out the progress they made. Perhaps according to him, the activities worked so well that the pupils had not the impression that by making less effort they could understand the concepts better and better.

Even if at the beginning, the teacher had concerns about possible disturbances research could have to the normal sequence of activities and about what this research could bring him as a teacher. However, he considers that because of the adaptation, the activities took place in a natural manner. As a matter of fact, the teacher considers that activities were advantageous to him as well as to his pupils and constitute a very good introduction to kinematics. Moreover, our observations confirm that the approach was well suitable for the style of the teacher, notably he demonstrated the faculty to ask good questions to the pupils, to grab in flight their comments and that in general he controlled and managed activities well.

\section{METHODOLOGY}

Our pilot study consisted of a class of 32 French-speaking pupils, that is 18 girls and 14 boys, of a 11th grade physics course given in a high school of the province of Ontario in Canada. The pupils of this class had chosen a science orientation program of studies given by the school so that it is assumed they are interested by sciences. The teacher involved in this research had a teaching experience of 20 years and already tested a similar strategy the previous year [18]. The approach described in the previous section took place during five successive periods of one hour and quarter at the very beginning of the second semester. Besides, two periods were added to the implementation of the VBL, a prior period to introduce activities to the pupils and a subsequent period to take an additional measure of pupils' understanding of constant speed motion. In each of these periods, the pupils had to answer a question taken haphazardly in a bank of problem during five minutes of the period. This disposition allowed us to follow the evolution of the understanding of every pupil throughout the experimentation of the strategy of the VBL.

To measure the evolution of understanding according to the number of periods dedicated to the use of the VBL, we conceived a test of understanding of the constant speed [19]. Since every pupil is measured at several occasions, conditions in which these measurements are taken may vary, that it is in the day of the week, the hour during day, etc. So, a pupil may not get the same result in answering questions of identical difficulty because he is tired or irritated during a particular occasion. In such a case, where the temporal dimension is important, the choice of an item response model must take into account the variations in the course of the time of the answers of the pupils. As such, the model with facets developed by Linacre [20] allows considering the influence of these different factors or 'facets' on the measure of understanding. The calculation of the different parameters linked to these factors (or facets) is made by the model equation which links up the values of parameters with observations [20]:

$$
\log [(\text { Pnijk }) /(\text { Pnijk-1) }]=(\mathrm{Bn}+\mathrm{Ti})-(\mathrm{Dj}+\mathrm{Fk})
$$

where:

Pnijk is likelihood that the pupil ' $\mathrm{n}$ ' sees itself granted a level ' $\mathrm{k}$ ' at occasion ' $\mathrm{i}$ ' when he answers question ' $\mathrm{j}$ '.

Pnijk-1 is likelihood that the pupil ' $\mathrm{n}$ ' sees itself granted a level ' k-1 ' at occasion ' $\mathrm{i}$ ' when he answers question ' $\mathrm{j}$ '.

$\mathrm{Bn}$ is the skill of the pupil ' $\mathrm{n}$ '.

$\mathrm{Ti}$ is the more or less easiness with which the pupils answer at occasion ' $\mathrm{i}$ '.

$\mathrm{Fk}$ is the difficulty linked to the jump of level k-1 at level $\mathrm{k}$.

The various properties of the Facets model make it an appropriate tool for our analysis [20]. Firstly, the various parameters calculated by the model from observations have the properties of an interval scale. Secondly, the model allows the calculation of values for all pupils during all occasions of measure, including missing data, which increases the power of the statistical tests used. In order to do so, the model calculates for every pupil a value of the logarithm of its likelihood to produce a correct answer to the question subjected to each of the periods of the experimentation. To determine if the VBL had an effect on the understanding of the pupils, a repeated measures analysis of the variance was performed of the computed values. This analysis allows us to compare the results of the pupils between the different occasions of measure and to determine if one of these results differs significantly from the others. This comparison can take a specific form called contrast [21]. To prove our research hypothesis, it is necessary to determine if the increase of understanding according to the number of periods of the implementation of the VBL is linear. As such, it is possible, with the aid of orthogonal polynomials to separate the contributions from the linear tendencies and higher polynomials (quadratic, cubic, etc). Besides, these elements of variance being independent to each other, they can be separately tested [21]. Nevertheless, the comparison of every pupil in comparison with himself may be correlated. This possible dependency between repeated measurements of the same pupil means that the repeated measures analysis of variance cannot be used unless the condition of sphericity is satisfied [22]. This test, called also Mauchly's test, imposes certain conditions on the matrix of variances and covariance [23]. When the result of the test of Mauchly exceeds the threshold alpha of 0.05 , we can consider that the condition of sphericity is satisfied and as a result that the analysis of variance by repeated measurements can be used.

\section{Results}

The figure 3 introduces the average values of understanding acquired by the pupils at every occasion of measurement, each value being calculated with the help of equation (1). By inspecting figure 3 , we note that, in spite of certain variations, there is a positive tendency in the increase of understanding. This linear tendency is significant at the threshold alpha $0.05(\mathrm{p}$ $<0.02$ ) according to the results of the analysis of the variance of the table 1 .

Moreover, we also notice the presence of significant tendencies of order 4 and 5. Let us note that the test of Mauchly $(p=0.98)$ points out that the condition of sphericity is satisfied 
and as a result that the analysis of variance by repeated measurements can be used. Finally, the omnibus test of the variance of repeated measurements points out that there is at least one of the averages which differs significantly from the others $(\mathrm{p}<0.000)$ at the threshold alpha 0.05 .

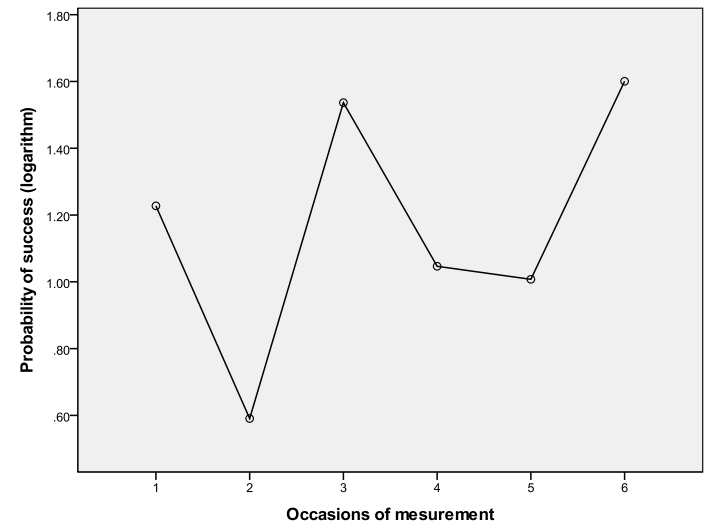

Figure 3. Average likelihood of success (logarithm) according to the number of periods

TABLE 1

Analysis of the variance of repeated measurements

\begin{tabular}{|l|l|l|l|l|l|l|}
\hline Source & Trend & $\begin{array}{l}\text { Sum of } \\
\text { squares }\end{array}$ & D.f. & $\begin{array}{l}\text { Mean } \\
\text { Squares }\end{array}$ & F & Sig. \\
\hline \multirow{5}{*}{ Factor } & Linear & 3.153 & 1 & 3.153 & 6.03 & .020 \\
\cline { 2 - 8 } & Quadratic & 1.861 & 1 & 1.861 & 2.79 & .105 \\
\cline { 2 - 8 } & Cubic & .146 & 1 & .146 & .31 & .579 \\
\cline { 2 - 8 } & Order 4 & 11.703 & 1 & 11.703 & 14.98 & .001 \\
\cline { 2 - 8 } & Order 5 & 5.550 & 1 & 5.550 & 13.04 & .001 \\
\hline \multirow{5}{*}{ Error } & Linear & 16.218 & 31 & .523 & & \\
\cline { 2 - 8 } & Quadratic & 20.691 & 31 & .667 & & \\
\cline { 2 - 8 } & Cubic & 14.460 & 31 & .466 & & \\
\cline { 2 - 7 } & Order 4 & 24.212 & 31 & .781 & & \\
\cline { 2 - 7 } & Order 5 & 13.194 & 31 & .426 & & \\
\hline
\end{tabular}

\section{DISCUSSION}

Our research is inspired by the constructivist approach, where the pupil constructs his knowledge by interacting with his environment. Given the difficulties pupils encountered in the physics course to gain conceptual understanding of kinematics concepts, we conceived a video-based laboratory (VBL), a specialized version of the usual computer-assisted laboratory, allowing the pupils to generate and prove hypotheses with the help of data collection and analysis softwares while discussing in small groups about videos of objects in motion.

Concerning the implementation of the VBL, the comments gathered during interviews with the pupils and the teacher show that these activities were advantageous to the pupils in their understanding of the different aspects of motion at constant speed. Some pupils appreciated the concrete character of activities which they prefered to lectures. A pupil even mentioned that he had made physics without realizing it. In the same vein, they could make links with mathematical notions such as the production and the interpretation of Cartesian coordinates as well as the calculus of the slope of a line. Moreover they familiarize themselves with the use of data collection and analysis softwares in the physics laboratory. Besides, it seems that the presentation format of motion phenomena as demonstrations did not prevent the pupils from considering these activities as laboratories [24].

However, improvements remain to be made with respect to the tutorials aimed to familiarize pupils to the collection and analysis software, notably by increasing their easiness of use (including pause, step and backwards functions) and by shortening the number of steps covered. In this respect, the teacher suggested to introduce the pupils in the handling of the softwares by giving them a prior training of around thirty minutes with the aid of a bank of activities already recorded under video. Perhaps one of the main obstacles to be overcome is the perception of the pupils regarding these activities. According to the teacher, the pupils did not have the impression to accomplish learning activities but rather consider them more as preparation to the physics course. This impression draws its source perhaps in the conceptions pupils may have of what constitutes learning in a physics course, constituted mostly by problem solving activities, as explained by the teacher. Besides, the emphasis put on the discussion of hypotheses between pupils runs opposite to pupils' conceptions of the role of laboratory in physics courses that mainly attempt to verify theories [25]. Moreover, according to the teacher, the time dedicated to this type of activities should not exceed five periods, owing to the lassitude which could manifest itself after some time. Finally, since discussion is one of the important elements of this approach, a particular attention must be turned to the linguistic and cultural aspects that can influence pupils' learning [26].

Concerning the effect of the VBL on the understanding of concepts of constant motion, our results point out that the curve of understanding according to the number of periods dedicated to the laboratory shows a positive and significant linear tendency. These results can point out that the VBL such as conceived has an effect on the understanding of the pupils. Indeed, observations noted in the research diary by the main researcher and the comments of the pupils and the teacher expressed during post-research interviews tend to corroborate these results. As such, the teacher mentioned that he noticed a constant progress in the understanding of the pupils of concepts of motion by the type of question which the pupils put down, by the quality of their explanation on the properties of motion phenomena, by their interpretation of the graphs, etc. However, the presence of significant tendencies of higher degree polynomials (of order 4 and 5) may point out to important fluctuations in results from one occasion to the other. These fluctuations can be caused by imprecision in measurement, variations in the interest and attention of the pupils according to the instant of the day when the measure was taken. It is also possible that these fluctuations are the result of swings linked up to transitions between levels of understanding [27]. 


\section{CONCLUSION}

This study undertaken with a single group of pupils cannot pretend to formulate conclusions that can be generalized to all high school pupils. As a result, these conclusions have a speculative character and are to be considered in the light of the exploratory aim of our study. This research adopts the perspective that the usage of computer science in the physics laboratory is revolutionizing the education of this discipline. However, computer-assisted experimentation is too often dedicated to the technical side of the data collecting and organization in form of tables and graphs. This emphasis on the technical precision of measurements, in spite of his rigor, risks of making us forget that it is often necessary for the pupils to develop their qualitative reasoning as well as their quantitative counterpart. However, it is not a question of leaving out the mathematization of the properties of phenomena but to consider it only when the essential elements of problem are qualitatively understood by the pupils. The approach introduced here use the capacities of the computer so that the pupil can, from common sense reasoning of a qualitative nature about properties of motion phenomena, make the transition to a mathematical representation in form of graphs of position-time and speed-time. Researches undertaken with several groups of pupils may help to confirm results obtained in the present study [28].

\section{REFERENCES}

[1] R.E. Anderson, "Reforming science teaching: What research says about inquiry". Journal of Science Teacher Education, vol. 13, no 1, pp. 1-12, 2002.

[2] A.B. Arons, A guide to introductory physics teaching, 2nd ed. Toronto: John Wiley \& Sons, 1997.

[3] R.D. Knight, Five Easy Lessons: Strategies for Successful Physics Teaching. San Francisco: Addison Wesley, 2004.

[4] F. Espinoza, "An analysis of the historical development of ideas about motion and its implications for teaching", Physics Education, vol. 40, no 2, pp. 139-146, 2005.

[5] G. De Vecchi, Enseigner l'expérimental en classe: Pour une véritable éducation scientifique. Paris : Hachette, 2006.

[6] P. Nonnon, and A. Métioui, "L'appropriation du processus de vérification expérimentale par des étudiants en formation des maîtres au secondaire : exemple de la diffusion de la chaleur dans un liquide", RES (Revue de l'Enseignement Supérieur), Academica, vol. 21, no 1, pp. 39-61, 2003.

[7] L. Trudel and A. Métioui, "Influence d'une discussion préalable sur la participation des élèves dans un laboratoire de physique du secondaire". Conférence Internationale Éducation, Économie et Société, Novotel Paris Tour Eiffel, 17-19 Juillet 2008, CD-ROM, pp. 410-424, 2008.

[8] A. Métioui and L. Trudel, "Analyse critique des expériences proposées dans les manuels destinés aux jeunes de 8 à 12 ans: Magnétisme, électrostatique et circuits électriques" . CD-ROM : Critical Analysis of School Science Textbooks, P. Clément (ed.), IOSTE International Meeting Tunisia Hammamet, 7 to 10 February, 12 pages, 2007.

[9] D. Jonassen, J Strobel and J. Gottdenker, "Model building for conceptual change", Interactive Learning Environments, vol. 13, no 1-2, pp. 15-37, 2005.

[10] C. Gianino, "Microcomputer-based laboratory for Archimedes' principle and density of liquids", The Physics Teacher, vol. 46, pp. $52-54,2008$

[11] E. Koleza and J. Pappas, "The effect of motion analysis activities in a video-based laboratory in students' understanding of position, velocity and frames of reference", International Journal of Mathematical Education, vol. 39, no 6, pp. 701-723, 2006.
[12] M. Riopel, Conception et mise à l'essai d'un environnement d'apprentissage intégrant l'expérimentation assistée par ordinateur et la simulation assistée par ordinateur. Thèse de doctorat, Montréal, Université de Montréal, 2005.

[13] L. Trudel, Impact d'une méthode de discussion sur la compréhension des concepts de la cinématique chez les élèves de cinquième secondaire. Thèse de doctorat, Montréal, Université du Québec à Montréal, 2005.

[14] J.Y. Lin, "Responses to anomalous data obtained from repeatable experiments in the laboratory", Journal of Research in Science Teaching, vol. 44, no 3, pp. 506-528, 2007.

[15] D.W. Russell, K.B. Lucas and C.J. McRobbie, "Role of the Microcomputer-Based Laboratory Display in Supporting the Construction of New Understandings in Thermal Physics", Journal of Research in Science Teaching, vol. 41, no 2, pp. 165-85, 2004.

[16] G. Durliat and J.M. Millet, "L'informatisation des dosages phmétriques avec l'interface Orphy et le logiciel Regressi, EPI, vol. 64, pp. 163-172, 1991.

[17] H. Altrichter and M.L. Hollly, "Research Diaries", In Research Methods in the Social Sciences, chap. 2, B. Somekh et C. Lewin, Eds. Thousand Oaks (Californie) : Éditions SAGE, 2005.

[18] L. Trudel and A. Métioui, "A Second Order Cybernetic Model of Scientific Conceptual Understanding: The Case of Kinematics", Journal of Systemics, Cybernetics and Informatics, vol. 10, no 1, pp. 7-17, 2012.

[19] L. Trudel, C. Parent and R. Auger, "Développement et validation d'un test mesurant la compréhension des concepts cinématiques en physique au secondaire". Mesure et évaluation en éducation, vol. 31, no 1, pp. 93-120, 2008.

[20] T. G. Bond and C. M. Fox, Applying the Rasch model : Fundamental measurement in the human sciences, $2^{\text {nd }}$ ed. Mahwah (New Jersey) : Lawrence Erlbaum Associates, 2007.

[21] D.C. Howell, Méthodes statistiques en sciences humaines. Bruxelles : De Boeck, 2008.

[22] L. K. Edwards, Applied analysis of variance in behavioral science. New York : Marcel Dekkers Inc., 1993.

[23] K. Leik, Experimental design and the analysis of variance. Thousands Oak (Californie) : Pine Forge Press, 1997.

[24] Roth, Wolff-Michael, Campbell J. McRobbie, Keith B. Lucas and Sylvie Boutonné, "Why may students fail to learn from demonstrations? A social practice perspective on learning in physics", Journal of Research in Science Teaching, vol. 34, no 5, pp. 509-533, 1997.

[25] M. Larochelle and J. Désautels, "Of course, it's just obvious': adolescents' ideas of scientific knowledge". International Journal of Science Education, vol. 13, no 4, pp. 373-389, 2007.

[26] L. Rivard, "La langue: Outil pour construire son savoir en sciences", Spectre, vol. 28, no 1, pp. 32-36, 1998.

[27] N. Granott, "How microdevelopment creates macrodevelopment: Reiterated sequences, backward transitions, and the Zone of Current development". In Microdevelopment: Transition Processes in Development and Learning, N. Granott and J. Parziale, Eds. Cambridge: Cambridge University Press, 2002, pp. 213-242.

[28] R.E. Slavin, Educational research in the age of accountability. Boston: Pearson, 2007.

\section{AUTHORS PROFILE}

Dr. Louis Trudel is assistant professor at the faculty of education at University of Ottawa, Ottawa, Canada. He was awarded a Ph.D. in education at the Université du Québec à Montréal, Montreal, Canada. Dr. Trudel has published several papers on science education and the pedagogical applications of computer science to the field of education.

A. Métioui received his Ph.D. in didactics from Laval University, Canada, in 1987. He is currently a professor at the Département de Didactique, Université du Québec à Montréal, Montréal, Quebec. Dr. Métioui has several publications to his credit. His research interests involve teachers' and student's representations in science and technology, and the design of the interactive computer environments that take into account the students and scientific representations related to physics. 